\title{
Breve historia de una revancha. Teodoro Núñez Ureta versus la crítica de Lima en $1943^{1}$
}

Manuel Munive Maco

Instituto de Investigaciones Museológicas y Artísticas / Universidad Ricardo Palma

Teodoro Núñez Ureta (Arequipa, 1912 - Lima, 1988) fue uno de los más destacados acuarelistas peruanos y, sin duda, el muralista más prolífico. Este trabajo aporta información sobre los acontecimientos que lo llevaron a practicar paralelamente aquellas dos disciplinas pictóricas técnicamente antagónicas.

\section{Caricatura / Acuarelista / Pancho Fierro / Críticos de arte en Lima / Muralismo / Premio Nacional "Ignacio Merino"}

Teodoro Núñez Ureta (Arequipa, 1912 - Lima, 1988) was one of Peru's most outstanding watercolour artists and, without doubt, the most prolific muralist. This article offers information on the events leading him to practice in parallel these two technically conflicting artistic disciplines.

\section{Caricature / Watercolour artist / Pancho Fierro / Art critics in Lima / Muralism / "Ignacio Merino" National Prize.}

\section{UNO}

En 1933, a los 21 años, Teodoro Núñez Ureta fue deportado a Chile por el gobierno del dictador Sánchez Cerro. Su participación en las movilizaciones producidas en Arequipa contra ese régimen y haber sido autor de una caricatura que ridiculizaba el "servicio militar obligatorio" determinaron su alejamiento forzoso del país² (Fig.1).

1 La primera parte de este artículo se publicó, con algunas variantes, en el impreso distribuido durante la exposición antológica de Teodoro Núñez Ureta titulada "Gente de mi tierra", realizada en la sala "Pancho Fierro" de la Municipalidad de Lima, entre el 15 de agosto y el 23 de septiembre de 2012. Dicha muestra reunió un segmento representativo de su producción plástica, fundamentalmente en acuarela. El autor agradece al señor Eduardo Moll y a Richard Estrada, de la Galería y Consultoría de Arte Moll, por su invalorable ayuda durante el proceso curatorial al facilitarnos el acceso a algunos coleccionistas de la obra de Núñez Ureta, especialmente al Dr. Alberto Musso quien, desinteresadamente, prestó varias pinturas emblemáticas y quien nos contactó, a su vez, con la señora María Malachowski, cuya colaboración fue crucial para el éxito de la muestra y para este escrito pues los documentos empleados en la redacción de la segunda parte proceden del álbum de recortes periodísticos del artista que ella conserva y que puso a nuestra disposición con suma generosidad. Agradecemos también al destacado artista plástico Alonso Núñez Rebaza, hijo del homenajeado, quien nos proporcionó, además de pinturas y reveladores bocetos de murales, información valiosa sobre el trabajo de Teodoro. Finalmente expresamos nuestra gratitud a la Lic. Patricia Mondoñedo. coordinadora de la galería "Pancho Fierro", por su ayuda durante todo el proceso curatorial así como al Departamento de Cultura de la Municipalidad por cedernos el uso de las fotografias de las obras que ilustran este artículo.

2 Con respecto a la práctica de la caricatura, Núñez Ureta manifestó: "Creo que la caricatura es el mejor medio para penetrar en el espíritu del hombre. Un verdadero y noble género artístico con profunda trascendencia social. No me refiero naturalmente a la caricatura entendida como la grosera deformación física de tal o cual personaje con el fin de adularlo o herirlo. Hablo de la verdadera caricatura, de aquella que sirvió a los griegos de Alejandría para expresar el dolor de su caída, de la que en la época medioeval pudo decir con tanta fuerza el misticismo religioso de una muchedumbre que en buena hora olvidó la frialdad de los perfectos modelos clásicos..." (1940). 
Fue así que desde muy joven, el artista arequipeño aprendió dos lecciones cruciales: que una postura ideológica debe ser respaldada mediante la acción, a pesar de los riesgos y si es que la realidad lo exige, y que el ejercicio del arte es una responsabilidad social y en absoluto un divertimento hedonista o una simple afición. Ya en mayo de 1933, la primera página del semanario chileno Zigzag publicó un apunte arquitectónico a pluma de nuestro artista ${ }^{3}$.

Al parecer el destierro no le impidió trabajar incansablemente de modo que muy pronto completó una serie de dibujos que expuso en la Casa Patiño Mc-Iver en Santiago de Chile a partir del 12 de agosto de 1933. El catálogo de aquella exposición consigna noventa dibujos cuyos títulos nos hacen pensar en los temas que desarrollará a lo largo de toda su obra: "Gamonal", "La Chichera", "Picantería", "Maestro de Escuela", "El Escribano", así como vistas andinas tales como "Balsa (Lago Titicaca)", "Antiguo Templo de Juliaca (Perú)", "Campanario de San Blas, Cusco (Perú)", etc. En el país sureño permaneció poco menos de un año.

De nuevo en su ciudad natal, siguió ejercitándose en el dibujo y la pintura y entre 1935 y 1936 se inició en el periodismo en el diario El Sur, firmando sus artículos con el seudónimo de Zontarín. En mayo de 1936 la Facultad de Letras de la Universidad de San Agustín de Arequipa le confirió el título de Doctor en Filosofia, Historia y Letras; y desde entonces hasta 1951 se encargó del dictado de los cursos de Historia del Arte y Estética.

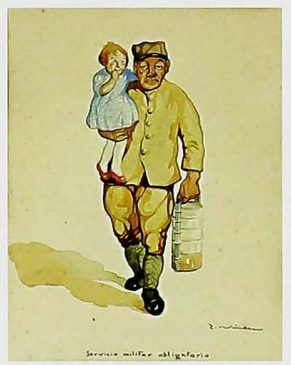

Fig.1. Servicio militar obligatorio, 1935 Acuarela, $29 \times 23 \mathrm{~cm}$. Colección particular.
Para una comprensión de la doble vertiente de su trabajo intelectual como escritor y artista plástico, resulta útil atender su singular periplo formativo: Núnez Ureta, que eligió el camino de la educación universitaria y, posteriormente, como Doctor en Filosofia, se desempeñó como catedrático de Estética, sin embargo optó por ser autodidacta para convertirse en artista. "Siguiendo a alguien no se llega a ninguna parte", sostuvo categóricamente en una entrevista de 1954 con respecto al aprendizaje sistematizado en una escuela o academia. Por eso, partió de una intuición singular: confió, con fervor, en que es el pueblo el que elige y modela a sus artistas, quienes asumen como una misión personal el expresar su "espíritu verdadero". Con esto quiso decir también que el talento artístico es algo que no se aprende sino que se lleva dentro; y que el vínculo profundo del artista con su pueblo esclarece y refina. Esta idea recorrió sus escritos como historiador y crítico del arte y sus reflexiones como artista plástico a lo largo de su vida.

Las influencias que respaldan esta ética son inmejorables: Pancho Fierro -artista de cuya vida y obra se convirtió en experto-y Mario Urteaga, otro autodidacta, a quienes consideraba los fundadores de la pintura peruana (tal como escribió en el agudo y diáfano ensayo que sirvió de introducción a los dos volúmenes dedicados a la pintura peruana contemporánea que el Banco de Crédito publicó en 1975 y 1976). Ambos pintores no solo se auto educaron como tales, sino que permanecieron conectados con sus entornos: el primero, a la bulliciosa Lima ochocentista, y el segundo, a la apacible campiña cajamarquina. Para Núñez Ureta, lo que el viaje de estudios a Europa aportó a los pintores peruanos del XIX,

3 Zigzag. Semanario Nacional. Santiago de Chile, 12 de mayo de 1933. 
como Merino, Laso y Montero, no tiene comparación con lo que Fierro y Urteaga ganaron al mantenerse ligados a sus terruños. (En ese sentido, es inevitable que encontremos similitudes entre las ideas de nuestro pintor y el pensamiento de José María Arguedas, quien también se sentía salvado como artista por su conexión con lo indígena y que temía, al igual que Núñez Ureta, la amenaza de la modernidad para la preservación de las tradiciones populares. Ambos hicieron de la evocación de los paisajes que los vieron nacer un incentivo permanente para su trabajo creativo).

"Será la intensidad del mensaje, el vigor de la expresión, la carga humana que pongamos en ella, lo que concederá universalidad a la obra hecha. [...] Recuérdese que la mayoría de los artistas que intervienen en el desarrollo del arte nacional son gente de provincia" (Núñez Ureta 1976:17-18).

Sobre el autodidacta cajamarquino puntualiza: "En verdad, es Mario Urteaga el primero que se acerca al paisaje peruano con amoroso respeto y mueve en él a sus indios de carne y hueso por primera vez. Por eso hemos dicho que Mario Urteaga cerrando el siglo XIX, comienza en verdad la auténtica pintura del Perú" (Núñez Ureta 1976) ${ }^{4}$.

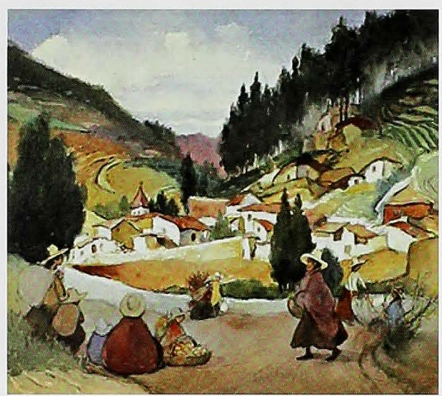

Fig.2. Paisaje de Tarma, s/f. Acuarela, $51 \times 57 \mathrm{~cm}$. Colección Ruiz de Somocurcio.

Para Núñez Ureta el "paisaje" es a la vez que espacio geográfico un ámbito generador de cultura:

Estuvimos todo el siglo muy ocupados en ir y volver de Europa y nuestros artistas, hasta los más dotados, pasaron de largo frente a la inmensa y rica realidad de nuestro paisaje y nuestra gente. ¿Por qué, por ejemplo, no hay pintores paisajistas en el siglo XIX? El paisaje fue en Europa el verdadero campo en el que se produjo la liberación de la pintura de los lazos académicos. [...] El paisaje es una lección de humildad y, a la vez, un instrumento de rebelión. Se convierte en el camino al realismo, y más tarde, al impresionismo. [...] El único paisaje peruano es el de Ocopa que pintó Laso. Merino también hizo algunos paisajes, pero como estudios de taller. Los de Baca Flor son extranjeros y sin gran emoción. Hay pocas escenas de la ciudad, alguna puerta en Merino, unos arcos, unos techos en Laso y eso es todo (1976). (Fig.2).

Sostener la coherencia intelectual que estamos mencionando implicó que el suyo fuese un camino solitario: desconfiaba de lo no figurativo y de las veleidades de los "ismos" artísticos de posguerra que empezaban a difundirse por todo el mundo. Pero, a diferencia de quienes adoptaban esta posición por desinformación o prejuicio, Teodoro Núñez Ureta lo hacía con un fundamento vitalizado por su formación humanista y, especialmente, por haber avizorado en la Nueva York de 1944, gracias a la beca Guggenheim que le fue concedida, la efervescencia artística que la Gran Manzana iba a albergar en las siguientes décadas. Por otro lado, tampoco comulgaba con la ortodoxia indigenista, aunque los personajes y 


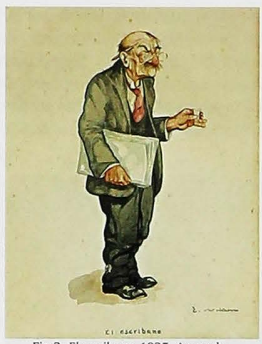

Fig. 3. El escribano, 1935. Acuarela $29 \times 23 \mathrm{~cm}$. Colección privada.

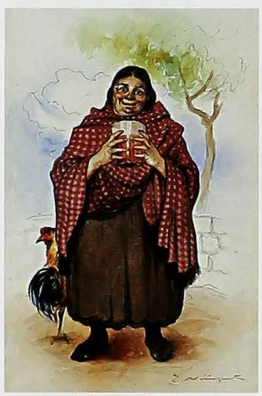

Fig.4. Chichera, ca.1970. Acuarela, $48 \times 30 \mathrm{~cm}$. Colección privada.

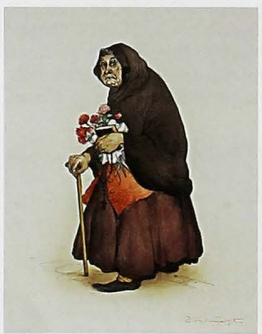

Fig.5. Beata, ca.1970. Acuarela, $45 \times 35 \mathrm{~cm}$. Colección privada. escenarios pintados durante toda su vida fueran, en gran parte, del mundo rural y mestizo de su tierra natal.

El tiempo suavizaría su juicio sobre los alcances del Indigenismo:

Pese a sus limitaciones y a la índole de cenáculo cerrado que tuvo su grupo, nadie podrá después del indigenismo, desatender en el arte la impresionante belleza de nuestro suelo ni la vida y el destino de sus habitantes. Después de más de un siglo de pintura sometida a los cánones académicos europeos, de un formulismo cansado y decadente, lleno de personajes literarios, de utilería de opereta y de retratos de familia, la lección que comenzara Pancho Fierro y que formulara cálidamente Mario Urteaga, se abre sobre todo el país. Debemos ver en ella un auténtico acto de independencia cultural. (Núñez Ureta 1976:13).

Al igual que Pancho Fierro, Núñez Ureta dirigió su mirada a las personas del pueblo -siervos, vendedores ambulantes, beatas, músicos callejeros, etc.-, en quienes reconoció una fuente de inspiración inagotable. Adoptó, también, la acuarela como técnica para erigir mediante un virtuoso y original dibujo "una burlona visión", tal como sintetizó en 1976 sus propias realizaciones en papel y lienzo. (Figs. 3, 4 y 5) Sin embargo, otro fue el tono de sus representaciones murales al fresco, donde la figura humana protagoniza alegorías monumentales sobre la educación, el trabajo o la Independencia, estilo que, en las últimas décadas de su vida, impregnó también en muchas de sus obras a la acuarela y al óleo.

Es curioso que Núñez Ureta haya practicado intensamente dos técnicas pictóricas antagónicas desde el punto de vista de su soporte y su perdurabilidad: la acuarela y el fresco. La primera, que le permitió llevar su obra a todos lados, sin embargo, al hallarse generalmente en colecciones privadas, se muestra eventualmente en una exhibición antológica similar a la que motivó este escrito. Por el contrario, el mural, técnica que él practicó entre 1944 y 1971, le permitió transmitir su mensaje en espacios públicos o, en todo caso, un poco más al alcance de todos. Para un artista autodidacta, el ejercicio del mural "al fresco" constituye una osadía pues ni siquiera los formados en las escuelas oficiales de artes plásticas han podido acceder a ello y mucho menos practicarlo.

\section{DOS}

A continuación ofrecemos una breve enumeración de las circunstancias que muy probablemente influyeron para que nuestro artista se convirtiera también en un verdadero maestro del muralismo. 
El 4 de junio de 1943, Teodoro Núñez Ureta presentó, en las instalaciones de la Sociedad "Entre Nous", su primera exposición individual en Lima, conformada básicamente por paisajes del sur del Perú. El catálogo consigna 42 acuarelas de "temática paisajista de Arequipa, Cusco y Puno".

La exposición fue un éxito comercial: alrededor de 30 obras se vendieron durante la primera hora de la ceremonia inaugural. En cuanto a su difusión, la cobertura en la prensa escrita fue completa. (Fig.6) Y en lo que respecta a la recepción crítica, todos los involucrados con ese oficio se pronun-

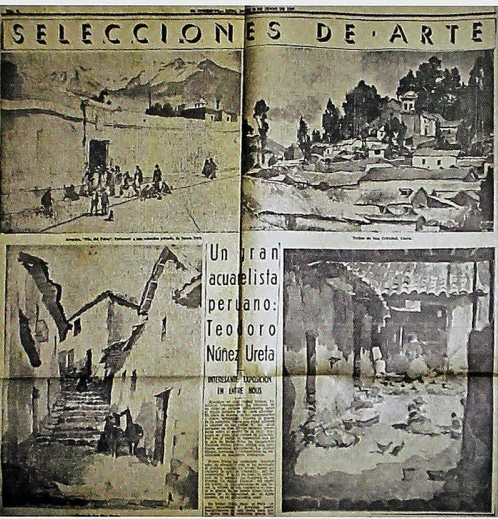

Fig.6. Recorte del diario El Comercio, junio 1943. ciaron: Carlos Raygada y Mercedes Gallagher de Parks, por un lado, publicaron reseñas favorables:

Raygada observa:

[...] La muestra de Núñez Ureta ofrece algunos aspectos predominantes sobre la línea general de sus cualidades pictóricas. Dos de ellos se acusan preferentemente: su capacidad de visión realista del paisaje -que comprende tanto los encantos mismos de la campiña arequipeña como el interés de las estructuras típicas de la arquitectura rural- y su admirable virtuosismo técnico. A estas características puede aún agregarse otra de particular significado artístico: el sentimiento interpretativo, que eleva al pintor sobre los niveles propiamente reales de su observación para colocarlo en un ángulo en que la fantasía impone sus derechos y le permite obtener preciosas transposiciones cromáticas y originales efectos plásticos. [...] (Raygada 1943).

Gallagher de Parks es encomiástica:

[...] a pesar de la belleza y excelente técnica de estas acuarelas, no nos habían preparado para la extraordinaria variedad y fuerza dentro de este género, que suele ser tan limitado, de la acuarela. ${ }^{5}$ [...] Núñez Ureta tiene una cualidad que es rara entre nuestros artistas, aun los de positivo talento, y es el buen gusto, expresión empleada aquí no en el sentido superficial en que generalmente se emplea sino en el de sólido criterio, que permite a un artista juzgar qué es lo que realmente sabe y puede hacer, y que impide que un buen pintor -o músico o escritor- fuerce su talento para plegarlo a ideas preconcebidas, haciéndole olvidar que un artista es un espíritu receptor de impresiones y encargado de la

5 El énfasis en ésta y las siguientes notas es nuestro. 
misión de transmitirlas al común de la humanidad transformadas en creaciones espontáneas. Ni debe ser esclavo del doctrinarismo académico ni del anti-académico que hoy impera [...] (Gallagher 1943).

Por otro lado, los críticos Raúl María Pereira y Juan Barreto fueron más bien adversos al señalar incisivamente la supuesta inferioridad de la acuarela como medio expresivo. El primero es particularmente ácido:

[...] La acuarela es un arte menor, y a menudo experimental. Núñez Ureta, catedrático universitario y hombre de sensibilidad, sabe que los medios de este género son muy limitados. Que no constituye un fin como el óleo o el fresco. Que no se puede construir con tan simple materia, y que por estas razones no puede prestarse a realizaciones de trascendencia, profundas. Ningún pintor lo es, por ser acuarelista [...] (Pereira 1943).

Barreto sigue los pasos de la argumentación anterior:

[...] En primer lugar, hemos de dejar sentado que la acuarela es, para nosotros, un arte esencialmente superficial, sobre todo cuando, como en el caso de Núñez Ureta, persigue casi únicamente la objetividad naturalista del objeto. La pintura al agua, aún en las obras de los maestros del género, no llega nunca a la nobleza, a la fuerza expresiva y profunda del óleo o la pintura mural. (Y no se crea que estamos juzgando a la acuarela por sus dimensiones físicas) [... De De Teodoro Núñez Ureta no podría decirse que es un pintor que se ha "roído el hueso íntimo" para hacer pintura. Su simplicidad paisana es ajena al angustioso y extremoso deber del artista, como lo entendemos nosotros, y con nosotros, muchos más [...] (Barreto 1943).

El joven artista, catedrático y periodista -es necesario precisar que obtuvo el Premio Nacional de Periodismo ese mismo año- enfrenta sin amilanarse las ideas esgrimidas por Pereira en dos textos extensos:

[...] En los largos párrafos de su artículo, se empeña el señor Pereira en probar que la acuarela no tiene importancia alguna en la pintura, que mis opiniones son arbitrarias, fruto de mi suficiencia y del desconocimiento de las grandes leyes del arte. Además, trata de probar que él es un crítico (Núñez Ureta 1943) ${ }^{6}$.

Sin embargo, aun cuando era obvio que las observaciones de Pereira y Barreto eran realmente burdas -y esto se hace mucho más claro hoy- Núñez Ureta prestó atención a lo dicho y al año siguiente realizó su primer mural al fresco en el Club Arequipa, "Quijote y Sancho Panza", suponemos que poco antes de su viaje de un año a los Estados Unidos.

Ha sido poco atendido el esfuerzo que implica aprender de modo autodidacta cualquier disciplina artística. En el caso de las artes plásticas, la acuarela ofrece cierta dificultad en la medida que prácticamente no admite correcciones. Sin embargo los colores "al agua", el papel y los pinceles pueden adquirirse con facilidad. Eso no ocurre con el fresco, cuya técnica compleja y exquisita requiere materiales y un método -y un espacio arquitectónico que lo acoja- cuyos secretos no eran impartidos permanentemente en nuestra Escuela Nacional de Bellas Artes. Por eso, investigar por su cuenta sobre la práctica del mural fue un reto para Núñez Ureta. (Que el protagonista de su primer fresco fuera el Quijote dice mucho de la dimensión heroica de ese esfuerzo).

6 Se trata de la respuesta a la refutación que Raúl María Pereira hizo a un artículo publicado por Núnez Ureta en la revista Estudios que fue reproducido por La Prensa. 


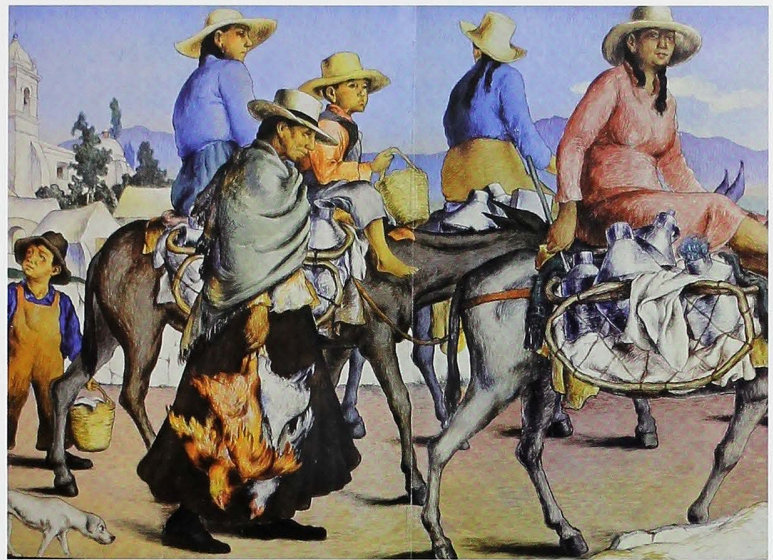

Fig.7. La campiña arequipeña, 1948. Mural (detalle). Tomado del libro de Luis E. Tord.

Su talento indudable y su tenacidad lo llevarían a realizar otros murales en su ciudad natal: "La campiña arequipeña" (1948) (Fig.7) y "La ciudad de Arequipa" (1950), ambos en el Hotel de Turistas, y "La Patria" en el Colegio Militar "Coronel Francisco Bolognesi" (1953). En Lima ejecutó los más ambiciosos en cuanto a sus dimensiones y a su complejidad alegórica: "La construcción del Perú" en el Ex Ministerio de Economía, Finanzas y Comercio (1954) (Fig.8); "Marinera limeña" y "Huayno" en el Edificio "Tacna" (1954); "La Educación en el Perú" en el Ex Ministerio de Educación (1955-1963) (Fig.9); "Miraflores I" y "Miraflores II" en el Municipio de Miraflores (1960) y "La Independencia del Perú" en el Panteón de los Próceres (1971). (Fig.10)

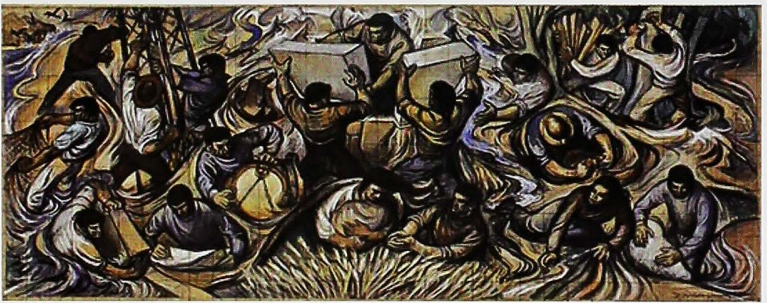

Fig.8. La construcción del Perú, ca.1954. Boceto del mural. Acuarela y lápiz sobre cartulina, 51 x $128 \mathrm{~cm}$. Colección del Museo de Arte de la UNMSM. 


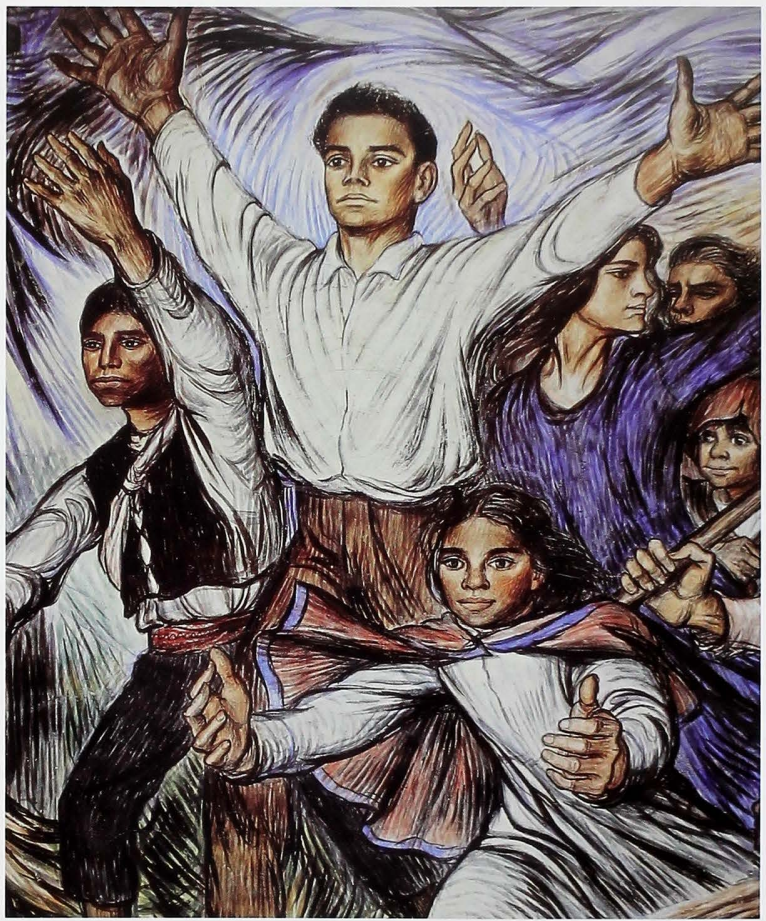

Fig.9. La educación en el Perú, 1955-1963. Mural (detalle). Tomado del libro de Luis E. Tord.

Sobre su técnica, Luis Enrique Tord precisa:

En cuanto a la manera de pintar sus murales, en Núñez Ureta predominó la del dibujante. No trabajó modelando las figuras con pincel ancho, sino haciendo reposar el carácter de las imágenes, su disposición esencial, en el dibujo, en la línea. Sus murales son entonces como grandes dibujos coloreados que recuerdan frecuentemente sus acuarelas, técnica que ejerció en él un predominio enorme hasta el punto de que algunas de sus composiciones muralísticas semejan acuarelas de grandes dimensiones (1989). (Fig.11). 


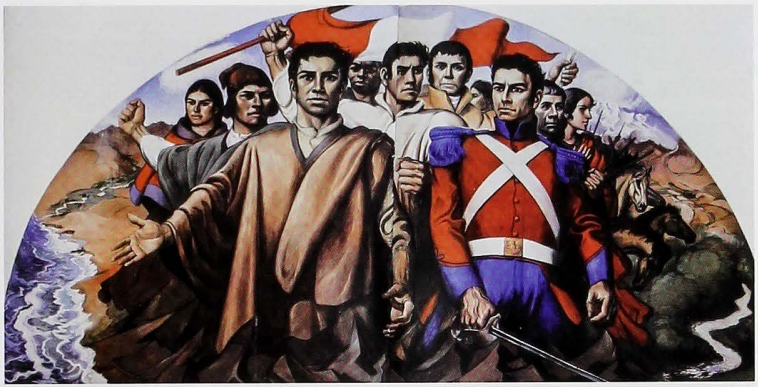

Fig.10. La Independencia del Perú, 1971. Mural. Tomado del libro de Luis E. Tord.

Cuando en 1943 Raúl María Pereira y Juan Barreto coincidieron en desahuciarlo como artista de la acuarela al compulsar, innecesariamente, esa "ligera" técnica con la perdurabilidad, monumentalidad y "nobleza" del fresco, no pudieron imaginar que apenas 11 años después el mismo pintor obtendría una distinción nacional al practicarlo y sin haberlo estudiado en escuela alguna y, mucho menos, sin haber renunciado al ejercicio de la acuarela: en 1954, por su mural "La construcción del Perú", Núñez Ureta obtuvo el Premio "Ignacio Merino" consagrándose como muralista. (Fig.12) Aquella fue una paciente e inteligente revancha que Núñez Ureta se cobró con sus críticos detractores y consigo mismo. Finalmente se convirtió en un exégeta de los muralistas mexicanos y particularmente de Siqueiros, al cual homenajeó poco tiempo después de haber fallecido pronunciando un discurso en el Instituto Nacional de Cultura en el verano de 1974.

Por otro lado, cuando buscó un sustento histórico para el ejercicio de la acuarela, pues era obvio que no podía aceptar los juicios peyorativos de sus primeros críticos limeños, se fue convirtiendo en acucioso investigador de la vida y la obra del mulato Pancho Fierro, al punto de haber encontrado documentos invalorables como su partida de bautizo y la de su matrimonio con Gervacia Cornejo.

Manuel Cisneros Sánchez, autor de uno de los estudios pioneros y rigurosos sobre la pintura de Fierro, fue categórico al señalar quién debía relevarlo en sus indagaciones:

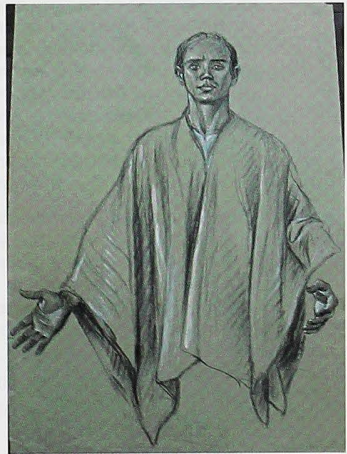

Fig.11. Estudio de personaje del mural La Independencia del Perú, ca.1971. Colección Alonso Núnez R.

Se ha escrito y se ha dicho bastante sobre Pancho Fierro, pero falta un estudio profundo de su obra, que pudiera establecer la composición y calidad de los 


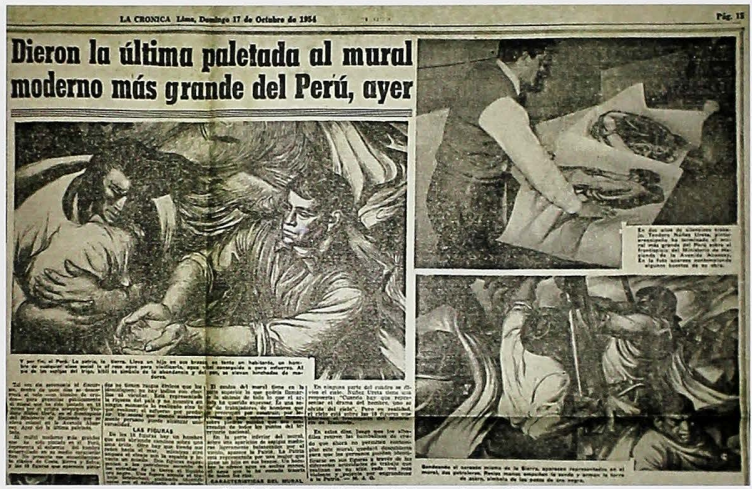

Fig.12. Recorte del diario La Crónica, octubre de 1954.

colores que utilizaba y la forma como los empleaba; la mayor o menor intensidad del dibujo previo y del sombreado; las dificultades, logros y errores de la composición; sus más saltantes características, incluyendo aciertos y defectos, etc. En realidad es un vacío que debe Ilenarse. [... Teodoro Núñez Ureta podría ser el más calificado para llenar el acotado vacío, dada la cabalidad de sus conocimientos y pleno dominio sobre la materia. Sería hermoso que el eximio artista arequipeño, que domina las diversas facetas de la pintura, pero que, en nuestra opinión, es nuestro gran acuarelista de la presente centuria, con merecida fama que ha traspasado nuestras fronteras, para consagrarse en museos extranjeros, pudiera dedicar algo de su quehacer al estudio de la obra del modesto Pancho Fierro, $\tan$ desconocido y desamparado en el ochocientos, pese a los innegables atributos que hoy sí se le reconocen (1975:215-216).

Teodoro Núñez Ureta se sentía cercano de Pancho Fierro en el aspecto técnico y temático: ambos fueron acuarelistas autodidactas y permanecieron inmersos en la vivencia popular que les brindaba los estímulos para producir un "arte auténtico". Y fue esta certeza la que lo llevó a auto educarse también como muralista, contraatacando, con una pertinencia insólita en el medio artístico local, a aquellos dos prejuiciosos críticos limeños que le atribuyeron una "simplicidad paisana" a su personalidad creativa. Suponemos que sus posteriores aportes a la crítica y la historia del arte terminaron por pulverizar a aquellos dos de quienes apenas si tenemos recuerdo. 


\section{Bibliografía}

\section{Barreto, Juan}

1943 "La exposición de Núñez Ureta", en Revista Excelsior (Lima), N. ${ }^{\circ} 123-124$, mayo-junio.

\section{Cisneros Sánchez, Manuel}

1975 Pancho Fierro y la Lima del 800. Madrid: Importadora, Exportadora y Librería García Ribeyro.

\section{Gallagher de Parks, Mercedes}

1943 "Calendario. La exposición de acuarelas de Núñez Ureta", en Mercurio Peruano (Lima), 7 de junio.

\section{Núñez Ureta, Teodoro}

1940 "De la caricatura al retrato y a la cátedra. Con el Doctor Teodoro Núnez Ureta, Catedrático de Estética e Historia del Arte en la Universidad de Arequipa", en La Prensa (Lima), 18 de marzo.

1943 "Algo más sobre la pintura y sus medios de expresión", en La Prensa (Lima), septiembre.
1976 Pintura contemporánea. Segunda parte 1920-1960. Lima: Banco de Crédito del Perú.

\section{Pereira, Raúl María}

1943 "La exposición Núñez Ureta", en $L a$ Prensa (Lima), [s.f].

\section{Raygada, Carlos}

1943 "De Arte... La exposición de acuarelas de Teodoro Núñez Ureta", en El Comercio (Lima), 12 de junio.

Tord, Luis Enrique

1989 Teodoro Núñez Ureta. Pintura mural. Lima: Banco Industrial del Perú.

\section{Zigzag}

1933 Zigzag. Semanario Nacional (Santiago de Chile), 12 de mayo. 
